ORIGINAL RESEARCH PAPER

\title{
INFLUENCE OF FRICTION PLATE ROUGHNESS ON THE EXTERNAL FRICTION ANGLE OF WHEAT KERNELS
}

\section{ZDZISLAW KALINIEWICZ*, ANDRZEJ ANDERS, KRZYSZTOF JADWISIEŃCZAK, PIOTR MARKOWSKI, ZBIGNIEW ŻUK}

\author{
University of Warmia and Mazury in Olsztyn, Oczapowskiego 11, 10-719 Olsztyn, Poland
}

*Corresponding author: zdzislaw.kaliniewicz@uwm.edu.pl

Received on 21 December 2018

Revised on 27 February 2019

\begin{abstract}
The aim of this study was to determine the correlations between the external friction angle of wheat kernels $v s$. the roughness of the friction plate and the basic physical properties of kernels. The average external friction angle ranged from $17^{\circ}$ to $24^{\circ}$, and its value increased with an increase in surface roughness. The analyzed relationship was well described by a logarithmic function. The dimensions, mass, geometric mean diameter, aspect ratio, sphericity index and density of wheat kernels had practically no influence on the angle of external friction, which indicates that wheat kernels cannot be reliably sorted based on their frictional properties.
\end{abstract}

Keywords: wheat kernels, physical properties, frictional properties, surface roughness, correlation

\section{Introduction}

Frictional properties are among the most important physical attributes of seeds. A sound knowledge of frictional properties is required for simulating and determining the parameters of seed transport, mixing, compaction and processing (Frączek, 1999; Frączek et al., 2003; Afzalinia and Roberge, 2007; Mahjoub et al., 2014).

In general, friction can be defined as a group of phenomena occurring at the point of contact between two materials. Friction causes moving objects to lose their energy, it leads to surface wear and can increase surface temperature (Frączek et al., 2003; Afzalinia and Roberge, 2007). Many theories that explain friction with different degrees of accuracy were proposed. They can be divided into three groups of mechanical, molecular and mechanical/molecular theories. Mechanical theories came first, and they attributed frictional resistance to surface asperities, frictional interactions between materials, elastic strain and plastic strain at the point of contact. Mechanical theories do not explain all aspects of friction, in particular on very smooth surfaces. Molecular theories describe interactions between the

https//doi.org/10.35219/foodtechnology.2019.1.08 
particles and atoms of materials that come into frictional contact. In the modern approach, friction is recognized as a phenomenon with a dual mechanical and molecular nature (Molenda et al., 1995; Frączek, 1999; Frączek et al., 2003; Afzalinia and Roberge, 2007). A recent approach to friction was developed by Frączek (1999) who postulated that friction force has three components: deformation, adhesion and cohesion. The above theory accounts for changes in the shape of surface asperities that tug each other, adhesion and cohesion between the surfaces that come into contact. According to Frączek (1999), adhesion plays the most important role in the external friction of plant seeds. Based on the characteristic features of plant materials, Frączek postulated that external friction is a function of load, surface roughness, density of asperity peaks, surface microhardness of granular material, elastic modulus, water content, real area of contact, and relative velocity of moving bodies that come into frictional contact. $\mathrm{He}$ observed that external friction is influenced by interrelated properties of materials that form a friction pair, in particular the ratio of roughness densities of two surfaces, the ratio of roughness of two surfaces, the ratio of elastic moduli, and the product of real contact area and seed hardness.

A similar approach to friction was proposed by Horabik (2001), Molenda and Horabik (2004), Afzalinia and Roberge (2007), Sharobeem (2007), Ibrahim (2008) and Bakun-Mazor et al. (2012) who observed that frictional properties of seeds are influenced mostly by the parameters of the friction surface (type, roughness), frictional characteristics (normal load, sliding distance, sliding velocity, seed orientation relative to the direction of movement), seed properties (moisture content, species, variety, ripeness, variations in shape) and external conditions (temperature and humidity).

According to Molenda et al. (1995), the frictional properties of seeds are determined by the geometric structure of the surface as well as seed roughness. However, most analyses of the frictional properties of various plant species indicate only the type of materials that constitute the friction pair (e.g. concrete, steel, wood) without describing their manufacturing precision. Therefore, published studies do not account for differences in surface smoothness which determines adhesion, and their results should be interpreted with caution.

The aim of this study was to determine the correlations between the external friction angle of wheat kernels vs. the roughness of the friction plate and the basic physical properties of kernels for modeling wheat grain sorting processes.

\section{Materials and methods}

The experiment was performed on 3 varieties of winter wheat such as Arktis, Jensen and Nelson, grown in the Region of Warmia and Mazury (northern Poland). The samples were composed of threshed kernels of every analyzed variety of winter wheat. Wheat was threshed with the Claas Lexion 750 combine harvester between the $3^{\text {rd }}$ and $6^{\text {th }}$ August 2015. Threshed kernels were stored in a closed container at room temperature for 6 months. Their relative moisture content was 
determined on a drying scale with a MAX 5-/WH halogen lamp (Radwag Radom, Poland). The analyzed wheat varieties were characterized by similar moisture content of $12.2-12.6 \%$.

The survey sampling method (Greń, 1984) was used to randomly select 50 kernels from initial samples of every wheat variety. Standard error of the mean values did not exceed $0.2 \mathrm{~mm}$ for the three basic dimensions of wheat kernels, $2.5 \mathrm{mg}$ for kernel mass, and $1^{\circ}$ for the angle of external friction.

In the first stage of the experiment, the angle of external friction $\gamma$ was measured with a device equipped with photodetectors (Bakier et al., 2015; Kaliniewicz et al., 2016; Kaliniewicz and Żuk, 2018). A friction plate made of S235 steel was fixed to an adjustable arm. The geometrical product specifications (GPS) of the friction plate, measured with the Diavite DH-5 (Bülach, Switzerland) surface roughness tester, were presented by Kaliniewicz and Żuk (2018). Kernels were placed on a horizontally inclined plate just above the light level of the top photodetector. The adjustable arm was lifted by a stepper motor with constant angular velocity of $1.25^{\circ} \cdot \mathrm{s}^{-1}$. When motion was initiated, the light beam was interrupted, the arm was automatically paused, and the kernel traveled down the friction plate along a distance of $25 \mathrm{~cm}$. The angle of inclination was measured to the nearest $0.01^{\circ}$. Kernels were placed on the plate with the crease down and the hilum down. Every kernel was measured in five replications. When three successive kernels were measured, the plate was wiped with cotton wool saturated with $40 / 60$ petroleum ether (Chempur Piekary Śląskie, Polska) to remove cutin.

In the second stage of the experiment, the length $L$ and width $W$ of wheat kernels were determined with the use of the MWM 2325 workshop microscope (PZO Warszawa, Poland) to the nearest $0.02 \mathrm{~mm}$ (one measurement consisted of two readouts from a thickness gauge with $0.01 \mathrm{~mm}$ resolution), and kernel thickness $T$ was measured with a device comprising a dial indicator (MasterTools, Kraków, Poland) with $0.01 \mathrm{~mm}$ resolution. The above measurements were performed according to the method described by Kaliniewicz et al. (2011, 2016). Kernel mass $m$ was determined on the WAA 100/C/2 weighing scale (Radwag Radom, Polska) to the nearest $0.1 \mathrm{mg}$.

The measured parameters were used to determine:

- geometric mean diameter $D$ (Equation 1), aspect ratio $R$ (Equation 2), and sphericity index $\Phi$ (Equation 3) (Mohsenin, 1986) of every kernel:

$$
\begin{gathered}
D=(T \times W \times L)^{1 / 3} \\
R=\frac{W}{L} \times 100 \\
\Phi=\frac{(T \times W \times L)^{1 / 3}}{L} \times 100
\end{gathered}
$$

- density $\rho$ (on the assumption that kernel shape resembles an ellipsoid) (Equation 4): 


$$
\rho=\frac{6 \times m}{\pi \times T \times W \times L}
$$

The results were analyzed statistically in the Statistica PL v. 12.5 program at a significance level $(\alpha)$ of 0.05 . The differences between the analyzed parameters of wheat kernels were determined by one-way analysis of variance (ANOVA). The normality of each group was verified by the Shapiro-Wilk test, and the equality of variances was assessed with Levene's test. Where the null hypothesis of equal population means was rejected, the differences were determined, and homogenous groups were identified with the use of Duncan's test. The correlations between the angle of friction and the remaining physical parameters of wheat kernels were determined by linear correlation analysis and non-linear regression analysis with data linearization that best fit the results (Rabiej, 2012).

\section{Results and discussion}

The physical parameters of the analyzed wheat kernels are presented in Table 1. The kernels of the evaluated wheat varieties differed mainly in density, which was the lowest in variety Jensen and the highest in variety Nelson. The remaining parameters differed only locally.

Table 1. Physical properties of kernels of the evaluated wheat varieties

\begin{tabular}{cccc}
\hline & \multicolumn{3}{c}{ Wheat variety } \\
\cline { 2 - 4 } Physical property & Arktis & Jensen & Nelson \\
& $\boldsymbol{x} \pm \boldsymbol{S D}$ & $\boldsymbol{x} \pm \boldsymbol{S D}$ & $\boldsymbol{x} \pm \boldsymbol{S D}$ \\
\hline Thickness (mm) & $3.03 \pm 0.19^{\mathrm{a}}$ & $3.08 \pm 0.18^{\mathrm{b}}$ & $3.04 \pm 0.20^{\mathrm{a}}$ \\
Width (mm) & $3.38 \pm 0.26^{\mathrm{a}}$ & $3.42 \pm 0.33^{\mathrm{ab}}$ & $3.46 \pm 0.31^{\mathrm{b}}$ \\
Length (mm) & $6.57 \pm 0.39^{\mathrm{b}}$ & $6.62 \pm 0.43^{\mathrm{b}}$ & $6.43 \pm 0.39^{\mathrm{a}}$ \\
Mass (mg) & $47.51 \pm 5.99^{\mathrm{a}}$ & $47.52 \pm 6.30^{\mathrm{a}}$ & $51.40 \pm 7.30^{\mathrm{b}}$ \\
Geom. mean diameter (mm) & $4.06 \pm 0.19^{\mathrm{a}}$ & $4.11 \pm 0.23^{\mathrm{b}}$ & $4.07 \pm 0.22^{\mathrm{a}}$ \\
Aspect ratio (\%) & $51.54 \pm 4.88^{\mathrm{a}}$ & $51.83 \pm 5.38^{\mathrm{a}}$ & $53.92 \pm 4.88^{\mathrm{b}}$ \\
Sphericity index (\%) & $61.94 \pm 3.21^{\mathrm{a}}$ & $62.26 \pm 3.15^{\mathrm{a}}$ & $63.42 \pm 3.06^{\mathrm{b}}$ \\
Density $\left.(\mathrm{g} \mathrm{cm})^{-3}\right)$ & $1.35 \pm 0.14^{\mathrm{b}}$ & $1.31 \pm 0.13^{\mathrm{a}}$ & $1.46 \pm 0.17^{\mathrm{c}}$ \\
\hline
\end{tabular}

$x$ - mean value, $S D$ - standard deviation; a, b, c - different letters denote significant differences in the value of the same parameter between the evaluated wheat varieties

The highest number of similarities was observed between the kernels of varieties Arktis and Jensen, and the smallest number of similarities - between the kernels of varieties Jensen and Nelson. The thickness of Arktis and Nelson kernels was similar to that noted in wheat varieties Zyta (Geodecki and Grundas, 2003), Baroudeur (Mabille and Abecassis, 2003), Kunduru-1149 (Başlar et al., 2012), Banti (Warechowska et al., 2013) and Jonong (Kim et al., 2014), whereas the thickness of Jensen kernels most closely resembled that of wheat variety Keumkang (Kim et al., 2014). An analysis of kernel width revealed similarities between variety Arktis and wheat varieties Tonacja (Zapotoczny, 2009), Pehlivan (Kalkan and Kara, 2011), Namhae, Ol, Tapdong and Younbaek (Kim et al., 2014), between variety Jensen and wheat varieties Vinjett (Zapotoczny, 2009), Olgeuru 
and Sukang (Kim et al., 2014), and between variety Nelson and wheat varieties Soissons 93 A4 (Mabille and Abecassis, 2003), Shiraz (Karimi et al., 2009), Korweta and Oberkulmer Rotkorn (Markowski et al., 2013) and Keumkang (Kim et al., 2014). An analysis of average kernel length revealed similarities between varieties Arktis vs. Uri (Kim et al., 2014), Jensen and Marvdasht (Kasraei et al., 2015), and varieteies Nelson vs. Anbaek, Gobun (Kim et al., 2014) and Korweta (Markowski et al., 2013). The above measurements indicate that the dimensions of the evaluated kernels did not differ significantly from the values given in the literature (Mabille and Abecassis, 2003; Hebda and Micek, 2005; Boac et al., 2010; Kim et al., 2014; Kasraei et al., 2015). For this reason, kernel mass and the calculated indicators of wheat kernels were also within the range of values reported for wheat in the literature.

The average angle of external friction of kernels of the analyzed wheat varieties (Table 2) ranged from $16.08^{\circ}$ (variety Jensen on a friction plate with surface roughness $R a=0.93 \mu \mathrm{m}$ ) to $25.51^{\circ}$ (variety Nelson on a friction plate with surface roughness $R a=8.16 \mu \mathrm{m}$ ). Significant differences in the values of external friction angles were not observed during successive measurements. The above results suggest that the angle of external friction is not significantly influenced by the sliding distance of threshed wheat kernels.

The average values of the angle of external friction determined for every kernel in five replications were used in further analyses. The external friction angles of kernels of the analyzed wheat varieties and the applied friction plates are presented in Table 3. In most cases, the lowest external friction angles were noted for wheat kernels of variety Jensen. The differences between the evaluated wheat varieties could be attributed to variations in the average height of asperities on kernel surfaces and the resulting differences in adhesion between kernels and friction plates. According to Fraczek (1999), these differences are determined by species and variety, and they are also influenced by the moisture content of kernels and location.

The external friction angle of wheat kernels was significantly influenced by surface roughness of the friction plate. In most cases, the value of the external friction angle increased with a rise in surface roughness. These results indicate that the surface that comes into contact with seeds has a decisive impact on friction. This is consistent with the observations made by Fraczek (1999) who noted that an increase in the roughness of the friction plate increases the deformation component of the friction force, which increases the extent to which the asperity peaks of hard structural material tug the surface of plant material. The average values of the external friction angle ranged from $16.26^{\circ}$ to $24.52^{\circ}$ within a corresponding interval of external friction coefficients of 0.29 to 0.46 , which is consistent with the results reported by other authors (Molenda et al., 1995; Kram, 2006; Karimi et al., 2009; Boac et al., 2010; Kaliniewicz, 2013; Markowski et al., 2013; Kaliniewicz et al., 2016). Similar values of external friction coefficients were determined in seeds of other plant species, including chickpeas (Konak et al., 2002), lentils (Amin et al., 2004), fenugreek (Altuntaş et al., 2005), coriander (Coşkuner and Karababa, 
2007), cowpeas (Kabas et al., 2007; Yalçin, 2007), barley (Markowski et al., 2010), castor beans (Gharibzahedi et al., 2011) and psyllium (Ahmadi et al., 2012).

The data presented in Table 4 suggest that the evaluated physical properties of seeds (basic dimensions, mass, geometric mean diameter, aspect ratio, sphericity index and density) are very weakly correlated with the external friction angle of wheat kernels. The analyzed correlations were practically significant $(r>0.4)$ in only 7 out of 144 cases. The highest number of significant correlations between the external friction angle and the other parameters was noted in wheat kernels of variety Arktis tested on a friction plate with surface roughness $R a=1.39 \mu \mathrm{m}$ (5 out of 8 cases). Arktis kernels tested on the above friction plate were also characterized by the highest values of the external friction angle (Table 3). This could be attributed to synergistic interactions between asperities on the surface of seeds and the friction plate, which produces a peak corresponding to the cohesion component in the overall friction force balance. Cohesion is significantly influenced by the real area of contact between a seed and the friction plate (Kaczorowski and Ślipek, 1996; Frączek, 1999; Horabik, 2001), which partially explains the observed correlation between the dimensions and mass of kernels vs. the angle of external friction.

Table 3. Significance of differences between the average values of the angle of external friction $\gamma$ of wheat kernels

\begin{tabular}{|c|c|c|c|}
\hline \multirow{2}{*}{$\begin{array}{c}\text { Roughness } \\
\text { parameter } \\
\operatorname{Ra}(\mu \mathrm{m})\end{array}$} & \multicolumn{3}{|c|}{ Angle of external friction in seeds of wheat varieties } \\
\hline & $\begin{array}{c}\text { Arktis } \\
x \pm S D\end{array}$ & $\begin{array}{l}\text { Jensen } \\
x \pm S D\end{array}$ & $\begin{array}{l}\text { Nelson } \\
x \pm S D\end{array}$ \\
\hline 0.38 & $18.25 \pm 1.55^{\mathrm{bA}}$ & $16.91 \pm 0.92^{\mathrm{aB}}$ & $16.53 \pm 1.25^{\mathrm{aA}}$ \\
\hline 0.93 & $18.37 \pm 1.77^{\mathrm{cA}}$ & $16.26 \pm 1.28^{\mathrm{aA}}$ & $17.23 \pm 1.87^{\mathrm{bA}}$ \\
\hline 1.39 & $22.48 \pm 2.33^{\mathrm{cB}}$ & $20.14 \pm 1.93^{\mathrm{aC}}$ & $21.26 \pm 1.85^{\mathrm{bB}}$ \\
\hline 3.25 & $22.05 \pm 2.04^{\mathrm{bB}}$ & $20.08 \pm 1.37^{\mathrm{aC}}$ & $23.54 \pm 2.02^{\mathrm{cC}}$ \\
\hline 5.86 & $24.02 \pm 2.30^{\mathrm{aC}}$ & $23.15 \pm 1.70^{\mathrm{aE}}$ & $23.65 \pm 2.13^{\mathrm{aC}}$ \\
\hline 8.16 & $22.35 \pm 1.62^{\mathrm{aB}}$ & $22.41 \pm 1.74^{\mathrm{aD}}$ & $24.52 \pm 2.18^{\mathrm{bD}}$ \\
\hline
\end{tabular}

$x$ - mean value, $S D$ - standard deviation; $\mathrm{a}, \mathrm{b}$ - different letters denote significant differences in the average values of the angle of external friction of seeds of the tested wheat varieties on the same friction plate; A, B, C, D, E- different letters denote significant differences in the average values of the angle of external friction of seeds of the same wheat variety on the tested friction plates.

Weak correlations between the angle of external friction and the physical properties of wheat kernels were also reported by Kaliniewicz et al. (2016) in a study of variety Nawra. The above findings indicate that frictional properties are not the most highly discriminating traits of wheat kernels. This observation is confirmed in practice where seeds are most often sorted with the use of sieves and pneumatic separators.

As mentioned previously, the value of the external friction angle is determined by surface roughness of the friction plate (Figure 1). An equation with the highest coefficient of determination $\left(\mathrm{R}^{2}=0.67\right)$ and the highest percentage of explained variation for both traits were noted in Nelson kernels, whereas the lowest 
coefficient of determination was observed in Arktis kernels. It should be noted that these parameters were measured in biological material, therefore, the obtained equations explain the analyzed correlations to a satisfactory degree, and they can be used for modeling and implementing operations relating to the processing, cleaning, sorting, transport and storage of wheat grain. The above correlations can be described with a logarithmic function to base $e$ (Euler's number). The coefficient of determination for the above function is 0.53 when the properties of kernels of all evaluated wheat varieties are analyzed in combination. According to the discussed equation, the angle of external friction on the tested friction plates can range from around $17^{\circ}$ to around $24^{\circ}$, which indicates that it can differ by up to $42 \%$ within the evaluated range of surface roughness values. Our results suggest that a reliable determination of friction force requires information about the type of friction plate as well as surface roughness.

Table 4. Pearson's coefficients of linear correlation between the angle of external friction $\gamma$ and the remaining properties of wheat kernels

\begin{tabular}{|c|c|c|c|c|c|c|c|}
\hline \multirow{2}{*}{$\begin{array}{l}\text { Wheat } \\
\text { variety }\end{array}$} & \multirow{2}{*}{$\begin{array}{l}\text { Physical } \\
\text { property }\end{array}$} & \multicolumn{6}{|c|}{ Plate roughness $R a(\mu \mathrm{m})$} \\
\hline & & 0.38 & 0.93 & 1.39 & 3.25 & 5.86 & 8.16 \\
\hline \multirow{8}{*}{ Arktis } & $T$ & 0.068 & -0.140 & $-0.436^{*}$ & -0.214 & $-0.341^{*}$ & -0.132 \\
\hline & $W$ & 0.069 & -0.151 & -0.562 & -0.194 & -0.191 & -0.033 \\
\hline & $L$ & 0.017 & 0.106 & -0.151 & -0.286 & -0.077 & 0.087 \\
\hline & $m$ & 0.021 & -0.197 & $-0.456^{*}$ & -0.130 & -0.216 & 0.027 \\
\hline & $D$ & 0.075 & -0.088 & $-0.564^{*}$ & $-0.344^{*}$ & -0.271 & -0.051 \\
\hline & $R$ & 0.034 & -0.162 & $-0.426^{*}$ & 0.003 & -0.130 & -0.089 \\
\hline & $\Phi$ & 0.043 & -0.203 & $-0.393^{*}$ & 0.019 & -0.214 & -0.148 \\
\hline & $\rho$ & 0.259 & -0.126 & 0.087 & 0.300 & 0.141 & 0.099 \\
\hline \multirow{8}{*}{ Jensen } & $T$ & -0.257 & -0.132 & $-0.416^{*}$ & -0.185 & -0.284 & -0.023 \\
\hline & $W$ & -0.287 & -0.109 & -0.217 & -0.010 & -0.249 & 0.192 \\
\hline & $L$ & 0.001 & -0.105 & -0.144 & -0.122 & -0.116 & 0.219 \\
\hline & $m$ & -0.207 & -0.028 & -0.244 & 0.070 & -0.292 & 0.207 \\
\hline & $D$ & -0.2718 & -0.147 & $-0.379^{*}$ & -0.133 & -0.288 & 0.177 \\
\hline & $R$ & -0.279 & -0.049 & -0.072 & 0.080 & -0.173 & 0.066 \\
\hline & $\Phi$ & $-0.303^{*}$ & -0.032 & -0.155 & 0.016 & -0.211 & -0.049 \\
\hline & $\rho$ & 0.140 & 0.240 & 0.265 & $0.510^{*}$ & -0.163 & 0.029 \\
\hline \multirow{8}{*}{ Nelson } & $T$ & -0.054 & 0.260 & 0.054 & 0.052 & $-0.369^{*}$ & 0.037 \\
\hline & $W$ & -0.067 & 0.176 & 0.142 & 0.074 & -0.037 & 0.243 \\
\hline & $L$ & -0.150 & 0.192 & -0.023 & 0.134 & -0.187 & 0.105 \\
\hline & $m$ & -0.140 & 0.092 & 0.097 & -0.077 & -0.266 & 0.158 \\
\hline & $D$ & -0.135 & $0.316^{*}$ & 0.079 & 0.103 & -0.273 & 0.167 \\
\hline & $R$ & 0.017 & 0.042 & 0.155 & -0.017 & 0.117 & 0.215 \\
\hline & $\Phi$ & 0.041 & 0.074 & 0.121 & -0.037 & 0.019 & 0.103 \\
\hline & $\rho$ & -0.006 & -0.224 & 0.016 & $-0.314^{*}$ & -0.031 & -0.016 \\
\hline
\end{tabular}

$T$-thickness, $W$-width, $L-$ length, $m$ - mass, $D$ - geometric mean diameter, $R$ - aspect ratio, $\Phi$ - sphericity index, $\rho$ - density; ${ }^{*}$ statistically significant correlations. 

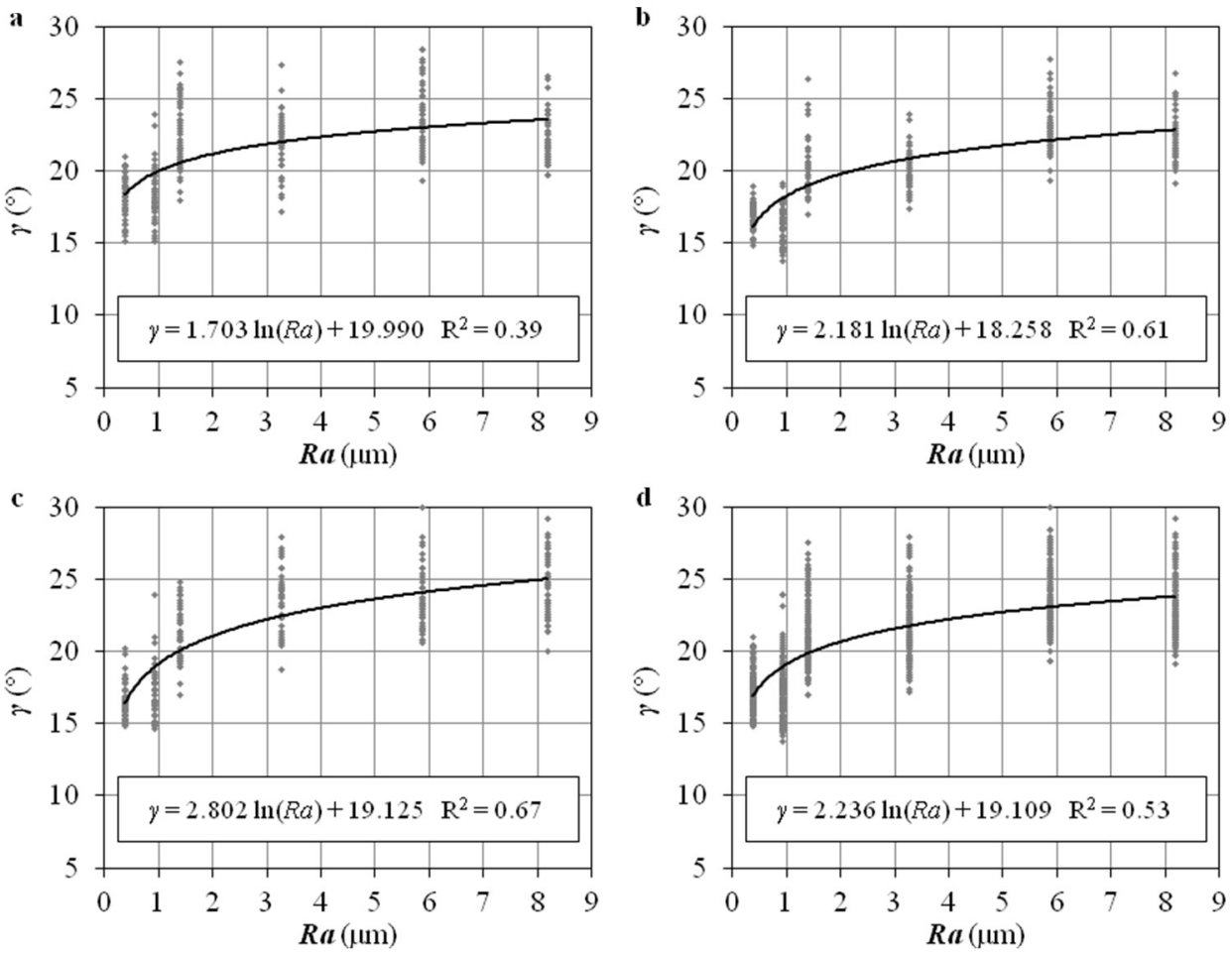

Figure 1. Relationships between the surface roughness $R a$ of the friction plate and the angles of external friction $\gamma$ of kernels of three wheat varieties: a) Arktis, b) Jensen,

c) Nelson, d) combined for all varieties.

\section{Conclusions}

The results of this study indicate that the geometrical structure of a friction plate significantly influences the external friction angle of wheat kernels. The above correlation is largely determined by wheat variety, and it can be described with a logarithmic function to base $e$. The external friction angle of wheat kernels ranged from $17^{\circ}$ to $24^{\circ}$, and its value increased with an increase in surface roughness of the friction plate.

In general, the surface of seeds is scarred when seeds move along a friction plate. However, in this study, significant differences in the external friction angle of threshed wheat kernels were not observed during replicate measurements, i.e. when kernels were initially placed on the friction plate and when they crossed a distance of $25 \mathrm{~cm}$ along the friction plate.

The dimensions, mass, geometric mean diameter, aspect ratio, sphericity index and density of wheat kernels do not influence the angle of external frictions on a steel friction plate. The above can be attributed to the surface properties of kernels of the evaluated wheat varieties which are characterized by greater variations than the geometric properties and mass of wheat kernels. Our results indicate that frictional 
properties should not be regarded as the main discriminatory traits during the cleaning and sorting of wheat kernels.

\section{References}

Afzalinia, S., Roberge, M. 2007. Physical and mechanical properties of selected forage materials. Canadian Biosystems Engineering, 49, 2.23-2.27.

Ahmadi, R., Kalbasi-Ashtari, A., Gharibzahedi, S.M.T. 2012. Physical properties of psyllium seed. International Agrophysics, 26, 91-93.

Altuntaş, E., Özgöz, E., Taşer, Ö.F. 2005. Some physical properties of fenugreek (Trigonella foenum-graceum L.) seeds. Journal of Food Engineering, 71, 37-43.

Amin, N.F., Hossain, M.A. and Roy, K.C. 2004. Effects of moisture content on some physical properties of lentil seeds. Journal of Food Engineering, 65, 83-87.

Bakier, S., Konopka, S., Lipiński, A., Anders, A., Obidziński, S., Bareja, K., Bajko, E. 2015. Innovative methods in agricultural engineering. Akademia Nauk, Komitet Agrofizyki PAN, Wydawnictwo Naukowe FRNA, Lublin (in Polish).

Bakun-Mazor, D., Hatzor, Y.H., Glaser, S.D. 2012. Dynamic sliding of tetrahedral wedge: The role of interface friction. International Journal for Numerical and Analytical Methods in Geomechanics, 36, 327-343.

Başlar, M., Kalkan, F., Kara, M., Ertugay, M.F. 2012. Correlation between the protein content and mechanical properties of wheat. Turkish Journal of Agriculture and Forestry, 36, 601-607.

Boac, J.M., Casada, M.E., Maghirang, R.G., Harner III, J.P. 2010. Material and interaction properties of selected grains and oilseeds for modeling discrete particles. Transactions of the ASABE, 53(4), 1201-1216.

Coşkuner, Y., Karababa, E. 2007. Physical properties of coriander seeds (Coriandrum sativum L.). Journal of Food Engineering, 80, 408-415.

Frączek, J. 1999. Friction of granular materials of plant origin. Zeszyty Naukowe Akademii Rolniczej im. H. Kołłątaja w Krakowie, Rozprawy nr 252, Kraków (in Polish).

Frączek, J., Kaczorowski, J., Ślipek, Z., Horabik, J., Molenda, M. 2003. Standardization of methods for the determination of the physical and mechanical properties of granular plant materials. Acta Agrophysica, 92, Rozprawy i monografie, Lublin (in Polish).

Geodecki, M., Grundas, S. 2003. Characterization of geometrical features of single winter and spring wheat kernels. Acta Agrophysica, 2(3), 531-538 (in Polish).

Gharibzahedi, S.M.T., Mousavi, S.M., Ghahderijani, M. 2011. A survey on moisturedependent physical properties of castor seed (Ricinus communis L.). Australian Journal of Crop Science, 5(1), 1-7.

Greń, J. 1984. Mathematical statistics. Models and tasks. PWN, Warszawa (in Polish).

Hebda, T., Micek, P. 2005. Dependences between geometrical features of cereal grain. Inżynieria Rolnicza, 6, 233-241 (in Polish).

Horabik, J. 2001. Physical attributes of loose plant material which are significant during storage. Acta Agrophysica, 54, monograph, Lublin (in Polish). 
Ibrahim, M.M. 2008. Determination of dynamic coefficient of friction for some materials for feed pellet under different values of pressure and temperature. Misr Journal of Agricultural Engineering, 25(4), 1389-1409.

Kabas, O., Yilmaz, E., Ozmerzi, A., Akinci, İ. 2007. Some physical and nutritional properties of cowpea seed (Vigna sinensis L.). Journal of Food Engineering, 79, 14051409.

Kaczorowski, J., Ślipek, Z. 1996. Modelling of the external friction kinetic process in plant materials. Part II. Determination of the real contact area during kinetic friction of plant materials. Annual Review of Agricultural Engineering, 1(1), 87-94.

Kaliniewicz, Z. 2013. Analysis of frictional properties of cereal seeds. African Journal of Agricultural Research, 8(45), 5611-5621. DOI: 10.5897/AJAR2013.7361

Kaliniewicz, Z., Anders, A., Markowski, P., Jadwisieńczak, K., Rawa, T. 2016. Influence of cereal seed orientation on external friction coefficients. Transactions of the ASABE, 59(3), 1073-1081.

Kaliniewicz, Z., Grabowski, A., Liszewski, A., Fura, S. 2011. Analysis of correlations between selected physical attributes of Scots pine seeds. Technical Sciences, 14(1), 1322.

Kaliniewicz, Z., Żuk, Z. 2018. A relationship between friction plate roughness and the external friction angle of wheat kernels. International Journal of Food Properties, 20(3), S2409-S2417.

Kalkan, F., Kara, M. 2011. Handling, frictional and technological properties of wheat as affected by moisture content and cultivar. Powder Technology, 213, 116-122.

Karimi, M., Kheiralipour, K., Tabatabaeefar, A., Khoubakht, G.M., Naderi, M., Heid, K. 2009. The effect of moisture content on physical properties of wheat. Pakistan Journal of Nutrition, 8(1), 90-95.

Kasraei, M., Nejadi, J., Shafiei, S. 2015. Relationship between grain physicochemical and mechanical properties of some Iranian wheat cultivars. Journal of Agricultural Science and Technology, 17, 635-647.

Kim, K.H., Shin, S.H., Park, S., Park, J.C., Kang, C.S. Park, C.S. 2014. Relationship between pre-harvest sprouting and functional markers associated with grain weight, TaSUS2-2B, TaGW2-6A, and TaCWI-A1, in Korean wheat cultivars. SABRAO Journal of Breeding and Genetics, 46(2), 319-328.

Konak, M., Çarman, K. Aydin, C. 2002. PH-Postharvest Technology: Physical properties of chick pea seeds. Physical properties of chick pea seeds. Biosystems Engineering, 82(1), 73-78

Kram, B.B. 2006. Research on the coefficient of external friction of corn grain in humidity function. Inżynieria Rolnicza, 3, 175-182 (in Polish).

Mabille, F., Abecassis, J. 2003. Parametric modelling of wheat grain morphology: a new perspective. Journal of Cereal Science, 37(1), 43-53.

Mahjoub, M., Movahhed, S., Chenarbon, H.A. 2014. Effective parameters on angle of repose, internal and external friction coefficient in two wheat varieties (Behrang and Shirudi). International Journal of Biosciences, 5(9), 117-124.

Markowski, M., Majewska, K., Kwiatkowski, D., Malkowski, M., Burdylo, G. 2010. Selected geometric and mechanical properties of barley (Hordeum vulgare L.) grain. International Journal of Food Properties, 13(4), 890-903. 
Markowski, M., Żuk-Gołaszewska, K., Kwiatkowski, D. 2013. Influence of variety on selected physical and mechanical properties of wheat. Industrial Crops and Product, 47, 113-117.

Mohsenin, N.N. 1986. Physical properties of plant and animal materials. Gordon and Breach Science Public, New York.

Molenda, M., Horabik, J. 2004. On applicability of a direct shear test for strength estimation of cereal grain. Particle and Particle Systems Characterization: Measurement and Description of Particle Properties and Behavior in Powders and Other Disperse Systems, 21(4), 310-315.

Molenda, M., Horabik, J., Grochowicz, M., Szot, B. 1995. Friction of wheat grain. Acta Agrophysica, 4, monograph, Lublin (in Polish).

Rabiej M. 2012. Statisctics in Statistica software. Ed. Helion, Gliwice (in Polish).

Sharobeem Y.F. 2007. Apparent dynamic friction coefficients for grain crops. Misr Journal of Agricultural Engineering, 24(3), 557-574.

Warechowska M., Warechowski J., Markowska A. 2013. Interrelations between selected physical and technological properties of wheat grain. Technical Sciences, 16(4), 281-290.

Yalçin İ. 2007. Physical properties of cowpea (Vigna sinensis L.) seed. Journal of Food Engineering, 79(1), 57-62.

Zapotoczny P. 2009. Discrimination of wheat seed varieties on the basis of geometrical characteristics. Inżynieria Rolnicza, 5(114), 319-328 (in Polish). 